\section{Remarkable Enhancement of Second-Order Nonlinear Optical Properties of Polynorbornenes Having Pendant Chromophores. Use of Hyper-Rayleigh Scattering to Estimate the Tacticity of Rigid Rod Polymers}

Jitendra A. Sattigeri, ${ }^{\dagger}$ Chung-Wai Shiau, ${ }^{\dagger}$ Chia Chen Hsu, $*+\frac{+}{}$ Fen-Fen Yeh, ${ }^{\ddagger}$ Sean Liou, ${ }^{\ddagger}$ Bih-Yaw Jin, ${ }^{*}, \dagger$ and Tien-Yau Luh*,†

\section{Department of Chemistry, National Taiwan University Taipei, Taiwan 106 Department of Physics National Chung Cheng University Ming-Hsiung, Chia-Yi, Taiwan 621}

Received September 28, 1998

Second-order nonlinear optical devices can be constructed by arranging the organic chromophores as pendants into a supramolecular backbone. ${ }^{1-4}$ Enhancement of such nonlinearity has been observed when chromophores are organized in a fixed noncentrosymmetric arrangement as side groups of helical polyisocyanide and polypeptide. ${ }^{1}$ However, no enhancement on the first hyperpolarizability $\beta_{0}$ values was observed for chromophores incorporated into a polymer with a flexible backbone. ${ }^{4}$ The use of more rigid polymers such as polynorbornenes (PNB) derived from the ring-opening metathesis polymerization (ROMP) of norbornene derivatives in optoelectronic applications has been briefly explored. ${ }^{5-7}$ The versatility of this methodology was demonstrated by synthesizing liquid crystalline polymers, ${ }^{5}$ electroluminescent polymers, ${ }^{6}$ and multiblock copolymers bearing various aryl chromophores to study their steady-state emission. ${ }^{7}$ We wish to report the first examples of using dipolar conjugated

$\dagger$ National Taiwan University.

¥ National Chung Cheng University.

(1) (a) Kauranen, M.; Verbiest, T.; Boutton, C.; Teerenstra, M. N.; Clays, K.; Schouten, A. J.; Nolte, R. J. M.; Persoons, A. Science 1995, 270, 965. (b) Verbiest, T.; Samyn, C.; Boutton, C.; Houbrechts, S.; Kauranen, M.; Persoons, A. Adv. Mater. 1996, 8, 756. (c) Verbiest, T.; Houbrechts, S.; Kauranen, M. Clays, K.; Persoons, A. J. Mater. Chem. 1997, 7, 2175. (d) Teerenstra, M. N.; Hagting, J. G.; Oostergetel, G. T.; Schouten, A. J.; Devillers, M. A. C.; Nolte, R. J. M. Thin Solid Films 1994, 248.

(2) (a) Liang, Z.; Dalton, L. R.; Garner, S. M.; Kalluri, S.; Chen, A.; Steier, W. H. Chem. Mater. 1995, 7, 941. (b) Verbiest, T.; Burland, D. M.; Jurich, M. C.; Lee, V. Y.; Miller, R. D.; Volksen, W. Science 1995, 268, 1604. (c) Yu, D.; Gharavi, A.; Yu, L. J. Am. Chem. Soc. 1995, 117, 11680. (d) Chen, T.-A.; Jen, A. K.-Y.; Cai, Y. J. Am. Chem. Soc. 1995, 117, 7295. (d) Wang, N. P.; Leslie, T. M.; Wang, S.; Lowel, S. T. Chem. Mater. 1995, 7, 185. (e) Lee, K.-S.; Moon, K.-J.; Woo, H. Y.; Shim, H.-K. Adv. Mater. 1997, 9, 978. (f) Dörr, M.; Zentel, R.; Sprave, M.; Vydra, J.; Eich, M. Adv. Mater. 1997, 9, 225

(3) (a) Ye, C.; Marks, T. J.; Yang, J.; Wong, G. K. Macromolecules 1987 20, 2324. (b) Jin, Y.; Carr, S. H. Marks, T. J.; Lin, W.; Wong, G. K. Chem. Mater. 1992, 4, 963. (c) Robello, D. R.; Dao, P. T.; Schildkraut, J. S. Scozzafava, M.; Urankar, E. J.; Willand, C. S. Chem. Mater. 1995, 7, 284. (d) Chen, T.-A.; Jen, A. K.-Y.; Cai, Y. Chem. Mater. 1996, 8, 607. (e) Nemoto, N.; Miyata, F.; Nagase, Y.; Abe, J.; Hasegawa, M.; Shirai, Y. Macromolecules 1996, 29, 2365. (f) Moroni, M.; Le Moigne, J.; Pham, T. A.; Bigot, J. Y. Macromolecules 1997, 30, 1964. 22819

(4) Song, O. K.; Woodford, J. N.; Wang, C. H. J. Phys. Chem. 1997, 106,

(5) (a) Maughon, B. R.; Weck, M.; Mohr, B.; Grubbs, R. H. Macromol ecules 1997, 30, 257. (b) Weck, M.; Mohr, B.; Maughon, B. R.; Grubbs, R. H. Macromolecules 1997, 30, 6430.

(6) (a) J.-K. Lee.; Schrock, R. R.; Baigent, D. R.; Friend, R. H. Macromolecules 1995, 28, 1966. (b) Boyd, T. J.; Geerts, Y.; Lee, J.-K.; Fogg, D. E.; Lavoie, G. G.; Schrock, R. R.; Rubner, M. F. Macromolecules 1997, 30, 3553. (c) Bellmann. E.; Shaheen, S. E.; Thayumanavan, S.; Barlow, S.; Grubbs, R. H.; Marder, S.; Kippelen, B.; Peyghambarian, N. Chem. Mater. 1998, 10, 1668.

(7) (a) Watkin, D. M.; Fox, M. A. J. Am. Chem. Soc. 1994, 116, 6441. (b) (a) Watkin, D. M.; Fox, M. A. Macromolecules 1995, 28, 4939. (c) Fossum, R. D.; Fox, M. A. J. Am. Chem. Soc. 1997, 119, 1197. (d) Stewart, G. M.; Fox, M. A. Chem. Mater. 1998, 10, 860.
Table 1. Photophysical Properties of $\mathbf{1}$ and $\mathbf{2}$

\begin{tabular}{cccccc}
\hline compd & $M_{\mathrm{n}}(\mathrm{PDI})$ & $n^{a}$ & $\lambda_{\max }(\mathrm{nm})^{b}$ & $\beta_{0}\left(10^{-30} \mathrm{esu}\right)^{b, c}$ & $\beta_{0}(\mathbf{2}) / \beta_{0}(\mathbf{1})$ \\
\hline 1a & & & 475 & 31 & \\
2a & $4200(1.1)$ & 13.5 & 469 & 178 & 5.7 \\
1b & & & 450 & $54^{d}$ & \\
2b & $10000(1.9)$ & 26 & 435 & $459^{d}$ & 8.5 \\
1c & & & 495 & 32 & 8.8 \\
2c & $11700(2.9)$ & 27 & 487 & 283 & \multirow{2}{*}{28.4} \\
1d & & & 393 & 28 & 16.4 \\
2d & $17000(1.3)$ & 44 & 384 & 459 & \\
\hline
\end{tabular}

${ }^{a}$ Number of repetitive monomeric unit. ${ }^{b} \mathrm{In} \mathrm{CHCl}_{3}$ solution. ${ }^{c}$ Measured at the fundamental wavelength $1480 \mathrm{~nm} .{ }^{d}$ Measured at the fundamental wavelength $1360 \mathrm{~nm}$.

moieties as pendants on a PNB backbone for the second-order nonlinear optical investigations.

Four different monomers 1 were synthesized (Scheme 1, Supporting Information). ${ }^{8}$ Grubb's ruthenium catalyst $\left(\mathrm{RuCl}_{2}\right.$ $\left(\mathrm{PCy}_{3}\right)_{2}(=\mathrm{CHPh})$ was employed to prepare the corresponding polymers 2. ${ }^{8,9}$ The $M_{\mathrm{n}}$ and polydispersity (PDI) of $\mathbf{2}$ as well as the absorption maxima in $\mathrm{CHCl}_{3}$ solution of both $\mathbf{1}$ and $\mathbf{2}$ are summarized in Table 1. The profiles of the absorption spectra of $\mathbf{1}$ and $\mathbf{2}$ are similar, although the absorption maxima for $\mathbf{2}$ are somewhat blue-shifted in comparison to those of the corresponding 1. ${ }^{10}$ Only $\mathbf{1 d}$ and $\mathbf{2 d}$ exhibited fluorescence emission at 497 and $492 \mathrm{~nm}$, respectively, no excimer formation being detected. Thermogravimetrical analyses showed that polymers $2 \mathbf{a}$ and $\mathbf{2 d}$ were stable at $220^{\circ} \mathrm{C}$, whereas $\mathbf{2 b}$ and $\mathbf{2 c}$ remained intact below $180{ }^{\circ} \mathrm{C}$.

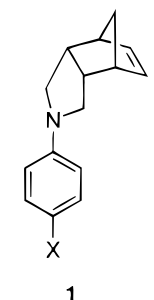

$\mathrm{X}:$

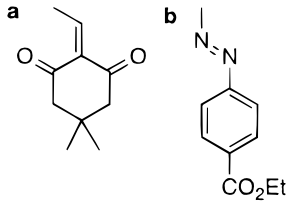

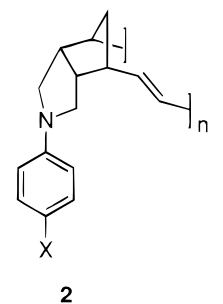

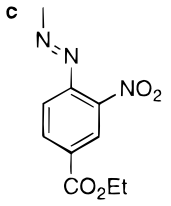

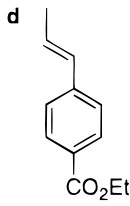

The hyper-Rayleigh scattering (HRS) method was employed to measure the $\beta_{0}$ values for $\mathbf{1}$ and $\mathbf{2}$ in $\mathrm{CHCl}_{3}$ which are also tabulated in Table $1 .^{11,12}$ It is interesting to note that the $\beta_{0}$ values are significantly enhanced in $\mathbf{2}$ in comparison with those of the corresponding monomers $\mathbf{1}$. A plot of the $\beta_{0}(\mathbf{2}) / \beta_{0}(\mathbf{1})$ having the same pendant chromophore versus the average number of repetitive monomeric units, $n$, in $\mathbf{2}$ gave a linear relationship with

(8) Scheme 1 is described in the Supporting Information.

(9) Walba, D. M.; Keller, P.; Shao, R.; Clark, N. A.; Hillmyer, M.; Grubbs, R. H. J. Am. Chem. Soc. 1996, 118, 2740.

(10) Such discrepancies have also been observed in other systems (ref 1b). There is a possibility that the pendent chromphores may form H-aggregate (Witten, D. G. Acc. Chem. Res. 1993, 26, 502; Yuzhakov, V. I. Russ. Chem. Rev. 1979, 48, 1076) which may provoke blue shifts in the absorption maxima for polymers relative to those of the corresponding monomers. Alternatively, the ring-strain difference in the polymers versus in the monomers may also cause discrepancy.

(11) (a) Clays, K.; Persoons, A. Phys. Rev. Lett. 1991, 66, 2980. (b) Hsu, C. C.; Huang, T. H.; Zang, Y. L.; Lin, J. L.; Cheng, Y. Y.; Lin, J. T.; Wu, H. H.; Wang, C. H.; Kuo, C. T.; Chen, C. H. J. Appl. Phys. 1996, 80, 5996. (c) Hsu, C. C.; Shu, C. F.; Huang, T. H.; Wang, C. H.; Lin, J. L.; Wang, Y. K.; Zang, Y. L. Chem. Phys. Lett. 1997, 274, 446. 


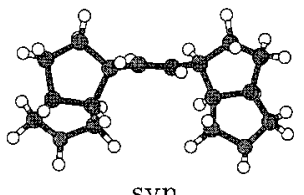

syn

\section{syndiotactic}

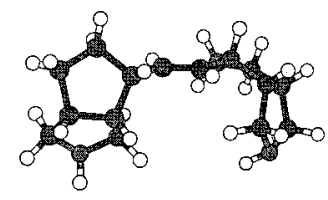

syn

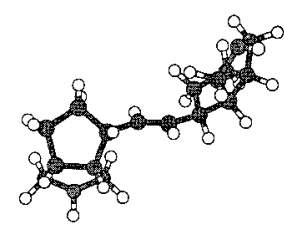

anti
Figure 1. The fully optimized conformations for the syndiotactic (syn and anti) and isotactic (syn and anti) dimers

a slope $0.36\left(R^{2}=0.984\right)$ and the intercept at the origin. These results indicated that each of the pendant chromphores contributes to approximately $36 \%$ of its monomeric $\beta_{0}$ values to the secondorder optical nonlinearity of the polymers and that the polymers 2 have a relatively rigid structure with uniform conformation.

ROMP of norbornenes by Grubb's ruthenium catalyst gives the polymers having mainly trans double bonds $(>90 \%) .{ }^{9}$ Although the ${ }^{13} \mathrm{C}$ NMR has been extensively employed for studying the tacticity of polymers, only a limited number of substrates have been investigated. ${ }^{13}$ Schrock et al. reported that polymers prepared by $\mathrm{Mo}\left(\mathrm{CHBu}^{\mathrm{t}}\right)$-catalyzed ROMP of norbornenes exhibit a much higher dielectric constant, and thus tacticity, than the corresponding atactic polymers prepared by employing $\mathrm{WCl}_{6} / \mathrm{SnMe}_{4}{ }^{14}$ In addition to tacticity, rotation about the single bond may occur, leading to conformational isomers, syn and anti. Figure 1 shows the fully optimized structures (by the AM1 method) of the dimers having trans double bonds without pendant chromophores. The relative energy of the two conformational isomers in each dyad are less than $1 \mathrm{kcal} / \mathrm{mol}$, and the barrier for the interconversion is less than $2 \mathrm{kcal} / \mathrm{mol}$.

The geometries of the dyads given in Figure 1 suggest that the syn conformation in the racemic dyad and the anti conformation in the meso dyad will likely generate a linear chain with longer persistent length. Accordingly, the constant temperature molecular dynamics (MD) calculations were carried out on octadecamer without a pendant group at room temperature using the open force

(12) The HRS experiments were similar to those described earlier (ref 11). The fundamental wavelength in this HRS experiment was chosen at a longer wavelength 1480 or $1360 \mathrm{~nm}$ to block the two-photon absorption process. A solution of 4-[N-ethyl- $N$-(2-hydroxyethyl)]-4'-nitroazobenzene (DR1) in $\mathrm{CHCl}_{3}$ was used as an external reference to determine the $\beta$ values of the samples. The dispersion free $\beta_{0}$ values of the samples were calculated by the undamped two-state model (Oudar, J. L. J. Chem. Phys. 1977, 67, 446).

(13) (a) Ivin, K. J.; Laverty, D. T.; Rooney, J. J. Makromol. Chem. 1977, 178, 1545. (b) Ivin, K. J.; Lapienis, G.; Rooney, J. J. Polymer 1980, 21, 436. (c) Ho, H. T.; Ivin, K. J.; Rooney, J. J. Makromol. Chem. 1982, 183, 1629. (d) Hamilton, J. C. Polymers 1998, 39, 1669. (e) Ivin, K. J.; Kenwright, A. M.; Hofmeister, G. E.; McConville, D. H.; Schrock, R. R.; Amir-Ebrahimi, V.; Carvill, A. G.; Hamilton, J. G.; Rooney, J. J. Makromol. Chem. Phys. 1998, 199, 547. (f) Carvill, A. G.; Greene, R. M. E.; Hamilton, J. G.; Ivin, K. J.; Kenwright, A. M.; Rooney, J. J. Makromol. Chem. Phys. 1998, 199, 687.

(14) Bazan, G. C.; Khosravi, E.; Schrock, R. R.; Feast, W. J.; Gibson, V. C.; O'Regan, M. B.; Thomas, J. K.; Davis, W. M. J. Am. Chem. Soc. 1990, 112,8378 .

(15) Computation results obtained using software programs from Molecular Simulations Inc.; dynamic calculations were done with the Cerius ${ }^{2}$ programs, using the OFF method. Semiempirical calculations were done with MOPAC7 program. The initial syn conformation was assumed for the syndio- and isotactic model system (Figure 2), and for $\mathbf{2 b}$ (Figure 3). MDOFF calculations were performed in gas phase at room temperature for $20 \mathrm{ps}$.
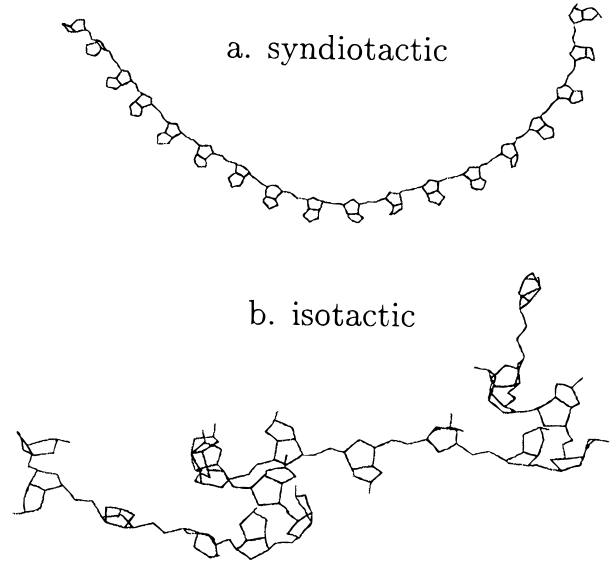

Figure 2. (a) The equilibrium conformation of the syndiotactic octadecamer without pendant group. (b) The equilibrium conformation of the isotactic octadecamer without pendant group.

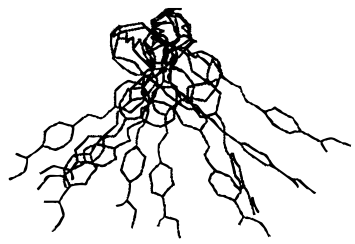

Figure 3. The equilibrium conformation of the syndiotactic form of the decamer $\mathbf{2 b}$ viewed from the end.

field (OFF) method implemented in the Cerius ${ }^{2} .15$ The equilibrium structures obtained from MD simulation are shown in Figure 2. The isotactic chain results in a random coil, whereas the substituents are aligned fairly well in the syndiotactic form. ${ }^{16}$ Introduction of pendant groups may provoke interactions between chromophores which may further stabilize the syn conformation. Indeed, the syndiotactic form of the decamer of $\mathbf{2} \mathbf{b}$ was calculated by the MD-OFF method, and the results are shown in Figure 3. It is interesting to note that the most stable conformation of the polymeric backbone is linear, with good alignment of the pendant chromophores. In comparison with the experimental results shown in Table 1, it seems likely that the polymers $\mathbf{2}$ may adopt this syndiotactic structure and each chromophore contributes coherently to the hyperpolarizability of the polymer. The strong enhancement of $\beta_{0}$ values observed in the HRS experiments can thus be rationalized.

In conclusion, we have demonstrated the significant enhancement of $\beta_{0}$ values for the non-centrosymmetric chromophores attached to a rigid polynorbornene backbone. The HRS method has been used for the first time as a convenient tool for the estimation of the tacticity of such polymers. Polymers obtained from the ruthenium-catalyzed ROMP of norbornenes have thus been assigned to have syndiotactic structure. The extension of this method to other rigid rod polymers and the potential for holographic applications ${ }^{17}$ are in progress in these laboratories.

Acknowledgment. This work was supported by the National Science Council of the Republic of China. Dedicated to Professor S. W. Tam on the occasion of his 65 th birthday.

Supporting Information Available: Scheme 1 for the syntheses of 1 and Figure 4 (the side view of the calculated syndiotactic form of decamer 2b) (PDF). This material is available free of charge via the Internet at http://pubs.acs.org.

JA983433Z

(16) We have also calculated PNBs 2 having cis double bonds. Both syndioand isotactic isomers exhibit random coil conformation. The persistent length is less than four monomeric units.

(17) Berg, R. H.; Hvilsted, S.; Ramanujam, P. S. Nature 1996, 383, 505. 